Max-Planck-Institut für demografische Forschung

Max Planck Institute for Demographic Research

Konrad-Zuse-Strasse 1 - D-18057 Rostock = Germany = Tel +49 (0) 3812081 - 0 - Fax +49 (0) 3812081 - 202 - www.demogr.mpg.de

MPIDR Working Paper WP 2019-024 I December 2019

(Revised January 2020)

\title{
The Limits to Fertility Recuperation
}

Daniel Ciganda I ciganda@demogr.mpg.de

Nicolas Todd I todd@demogr.mpg.de

This working paper has been approved for release by: Mathias Lerch (lerch@demogr.mpg.de),

Deputy Head of the Laboratory of Fertility and Well-Being.

(ㄷ) Copyright is held by the authors.

Working papers of the Max Planck Institute for Demographic Research receive only limited review. Views or opinions expressed in working papers are attributable to the authors and do not necessarily reflect those of the Institute. 


\title{
The Limits to Fertility Recuperation
}

\author{
Daniel Ciganda, Nicolas Todd
}

Max Planck Institute for Demographic Research

\begin{abstract}
The recently documented reversal of the association between socioeconomic development indicators and fertility rates suggests that a scenario of systematic fertility recuperation is not unlikely for a large number of countries in which fertility has fallen to low and very low levels. Although this reversal has been well-documented at the macro level, less is known about the individual-level dynamics behind it. Here, we propose and test a two-fold hypothesis about the micro-foundations of this reversal: In a first stage, advances in development drive the decline of fertility rates by contributing to the reduction of the share of unintended births (i.e., births associated with the absence or the inefficient use of contraception), and by promoting the reduction of desired family sizes as women enter the labor market. Once this first stage is completed, however, further advances in development might lead to the recuperation of fertility rates, as higher levels of education and resources may contribute to reduce the obstacles couples face when trying to achieve their desired family size. We test this hypothesis on France, Ireland, and Spain using an individual-level computational model of the reproductive process from which we simulate the maternity histories of post-baby boom cohorts. The simulations closely follow past fertility trends in all three countries. Forecasting the potential development of aggregate fertility indicators, the model predicts that even in the presence of a strong positive effect of development on fertility intentions, there are limits to the recuperation scenario imposed by further reductions in the time available for family formation, the already relatively small distance between desired and achieved fertility among recent cohorts, and the deceleration of the forces that could drive a return to higher fertility rates in the near future.
\end{abstract}




\section{Introduction}

The main focus of most theories of fertility change developed throughout the $20^{\text {th }}$ century was explaining the determinants of fertility decline, as if the continuation of the sustained downward trend observed in Western Europe since the mid $19^{\text {th }}$ century was the only possible scenario. An important exception to this view was the framework developed by Richard Easterlin, who argued that the baby boom after the Second World War and the subsequent baby bust resulted from a process of cyclical change in the relative socioeconomic standing of successive generations related to variations in cohort size (Easterlin, 1978). However, the baby boom echo predicted by Easterlin never materialized, and his hypothesis was largely abandoned. Indeed, the years that followed the baby boom were characterized by further declines in period fertility rates. The fact that a booming economy like West Germany was the first to reach low fertility levels in the early 1980s provided further support to modernization (or post-modernization) narratives, which assumed that economic and social development could only drive fertility decline (Caldwell and Schindlmayr, 2003).

Perceptions of the relationship between fertility and development started to change in the 1990s, when the Total Fertility Rate (TFR) stabilized in France, the Netherlands and the United Kingdom, and even increased slightly in Scandinavian countries, while it was reaching low and lowest-low levels in the south of Europe. Since then, a number of studies have documented the reversal of the long-term negative correlation between fertility rates and a series of social and economic development indicators at the macro level, such as female labor force participation (Rindfuss and Brewster, 1996; Ahn and Mira, 2002), the Human Development Index (Myrskylä et al., 2009), or GDP per capita (Luci-Greulich and Thévenon, 2014).

The idea that advances in development can cause fertility levels to increase received additional support after the sustained recuperation of period fertility rates that consolidated in the first decade of the $21^{\text {st }}$ century in most European countries (Goldstein et al. 2009). As a consequence, modernization frameworks like the Second Demographic Transition have lost some of their appeal in favor of more recent narratives, like those focused on gender-equality, that predict a return to more family as the dual-earner family gains normative status (Goldscheider et al., 2015; Esping-Andersen and Billari, 2015).

Importantly, the recuperation trend also prompted the United Nation's (UN) Population Division to revise upward the level at which the TFR was expected to converge in official population projections (United Nations, 2010). More recently, the UN has adopted a framework that uses two different models - one for the decline and another for the recuperation of fertility as the basis of its fertility projections (Raftery et al., 2014).

The universality of the recuperation trend has, however, been called into question by critics like Basten (2013), who argued that the fertility trajectories and existing family preferences in a group of high-income countries suggest that a recuperation scenario is very unlikely. 
Bongaarts and Sobotka (2012) have also questioned the idea of a sustained recuperation, claiming that a significant part of the increase in the Total Fertility Rate at the end of the 1990s can be attributed to the decelerating pace of the postponement transition and the gradual disappearance of distortions in the TFR caused by changes in the timing of family formation.

Both of these critiques are well-founded, the recuperation pattern is not universal and it is likely partially explained by timing distortions in the TFR that do not reflect real changes in the level of fertility. But even if this is the case, the question remains of whether the upward trend in the TFR could also be indicating a real recovery process in some countries, and to what extent development can contribute to increase fertility rates in the near future.

We believe that the answers to these questions lie in the joint analysis of the three transitions that have driven post-baby boom fertility in high-income countries: namely, the transition from the breadwinner to the dual-earner model, the transition to higher education, and the contraceptive transition.

Figure 1 illustrates the extent of the changes experienced by post-baby boom cohorts in these three domains. The rapid increases in the proportion of women with tertiary education and the proportion of women in the labor market have been accompanied by an equally dramatic decline in the proportion of unplanned births 1

It is important to think of these transformations as transitions in the demographic sense; i.e. as processes of change that represent the passage between two different regimes. This notion not only highlights the magnitude of the changes involved; it suggests that these changes will eventually come to an end.

\footnotetext{
${ }^{1}$ Unplanned births include mistimed and unwanted births; i.e., births that, from the perspective of the parents, occurred at an unexpected time or occurred after they had reached their desired family size.
} 
(a) Tertiary Education I Women, Cohort.

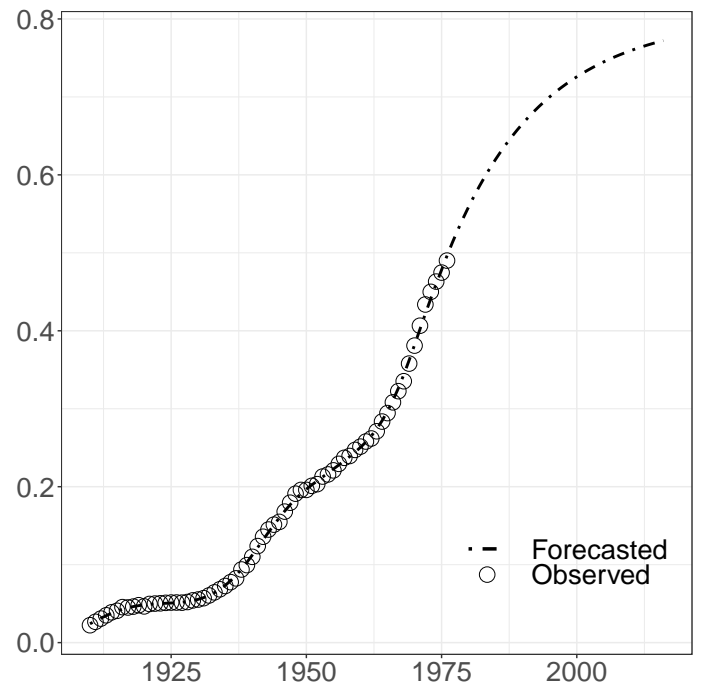

(b) Labor Force I Women, Cohort.

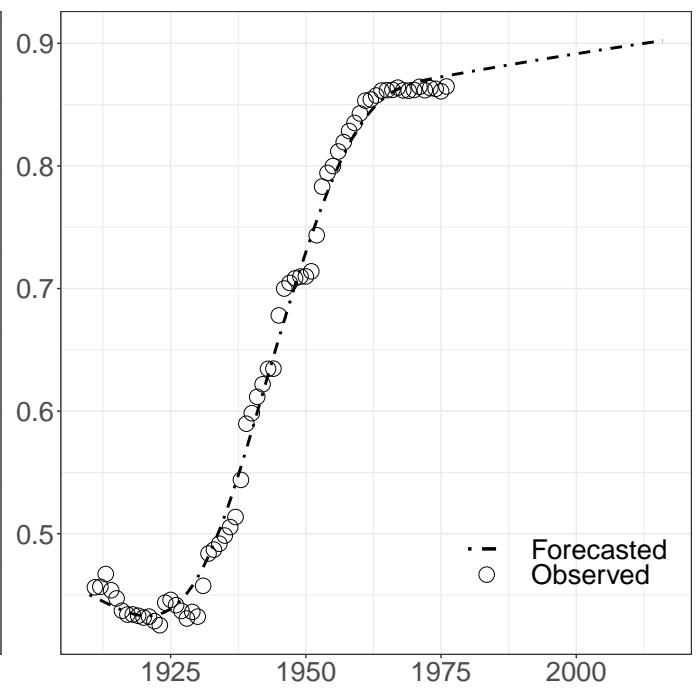

(c) Unplanned Births I Period.

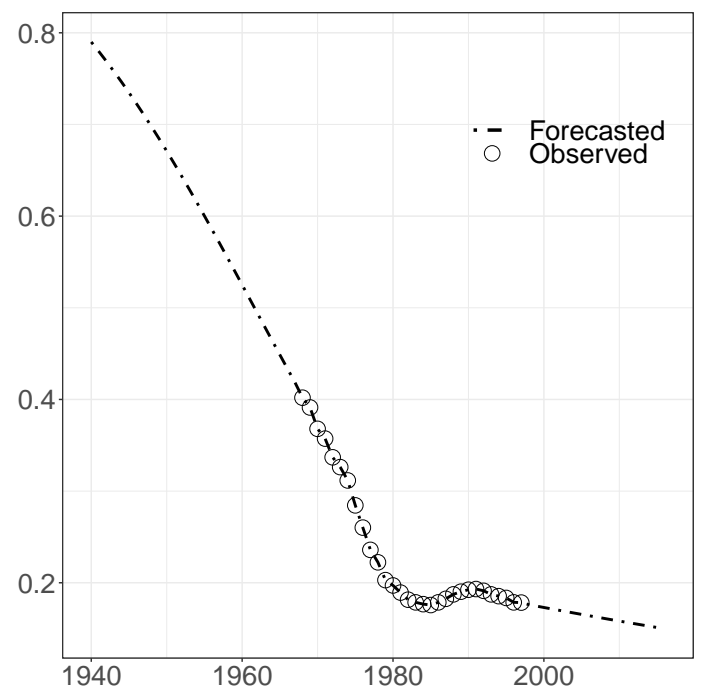

Figure 1: Transitions in Education, Contraception, Labor Force Participation in France.

Most analyses of post-baby boom fertility have focused exclusively on transitions in the education and labor force participation domains, reflecting a perception of post-baby boom fertility as a process entirely determined by individual choices.

The dismissal of the contraceptive transition is perhaps related to the fact that the methodology for measuring unplanned fertility, and the corresponding data collection efforts, were developed out of concerns for unmet family planning needs in developing countries (Klijz- 
ing, 2000), which also explains why the overwhelming majority of demographic analyses of unplanned fertility have focused on the regions covered by the Demographic and Health Surveys Program (Bongaarts, 1997; Casterline and El-Zeini, 2007, among others).

The few studies available in Europe, however, show that the role played by the reduction in unplanned births during the final stage of the fertility transition in Europe is larger than is usually assumed. Murphy (1993) estimated the impact of the introduction of the contraceptive pill in the fertility decline of the 1960s and 1970s in Britain, and claimed that most - if not all - of the change in fertility rates would have still occurred in the absence of the economic changes that were observed during this period. Similarly Régnier-Loilier et al. (2007) attributed half of the decline in fertility in the 1970s in France to the decrease in the proportion of unplanned births, and showed that this proportion has remained constant at about $20 \%$ since the mid-1980s.

These findings suggest that for a number of research questions - and especially those that involve pre-modern-contraception birth cohorts - fertility needs to be understood not as a single outcome, but as an aggregate of two outcomes: one that results from an intentional process, and one that results from an unintentional process (unplanned fertility).

Once this perspective is adopted, it is easier to see how education can have counteracting effects on fertility outcomes. While the expansion of education can depress total fertility by reducing the risk of unplanned pregnancies and incentivizing the postponement of the family formation process; it can also have a positive influence on intended fertility by increasing the resources available to couples, which can, in turn, help reduce the gap between desired and achieved family size.

We argue that the existence of counteracting effects of education on fertility outcomes, together with the transient nature of the changes that drove fertility change throughout the second half of the $20^{\text {th }}$ century, may be the keys to understanding post-baby boom fertility patterns.

More specifically, we believe that the transition to higher education, the transition to a dualearner model and the transition to a controlled reproductive process have triggered a series of positive and negative influences on fertility outcomes. These counteracting influences have been competing with varying relative strengths as these transitions moved forward. In a first, pre-modern contraception stage, the expansion of higher education contributes to fertility decline, both by reducing unplanned fertility and by promoting the participation of women in the labor market. During this first stage, the negative effects outpace any potential gains. But once the contraceptive transition and the transition into the labor market have been completed, the continuing expansion of education might result in the recuperation of fertility rates, provided the positive effect of increased resources is not outweighed by the negative effect of an even later onset of the family formation process.

To test our hypothesis, we use a computational approach to model the reproductive process, 
which allows us to derive aggregate fertility patterns from simulated reproductive trajectories, establishing a direct link between observed macro trends and individual behavior.

We fit our model to observed age-specific fertility rates from the 1960 s to the present, and to data on fertility goals and unplanned births (when available) in three countries with widely differing fertility trajectories in the European context: namely, France, Ireland, and Spain.

In addition to the information obtained during the estimation of the model, we obtain insights into our questions by exploring a number of scenarios that include forecasting aggregate fertility trends for the next 20 years.

The remainder of this article is structured as follows. After briefly expanding on our central hypothesis, we provide a description of the operation of the model, followed by an explanation of the procedure used for estimation. The results presented in Section 6 and the conclusions presented in Section 7 can be fully replicated by accessing the code and data available here: github.com/dciganda.

\section{Development and Fertility: Limits of Existing Ideas}

Two ideas derived from neoclassical economic models have dominated the debate on the effects of development on fertility rates: namely, the idea of opportunity costs and the idea of a quantity-quality trade-off (Becker and Lewis, 1973; Becker and Tomes, 1976).

The popularity of these notions lies in their perceived ability to readily explain the observed negative association between increasing resources and fertility. A closer look shows, however, that neither the opportunity costs nor the quality of children mechanisms are enough to generate the negative relationship found between development and fertility (Jones et al., 2008). This negative relationship does not emerge in neoclassical frameworks until restrictive additional assumptions are included in the models: namely, that the time needed to raise a child is exclusively incurred by the parents (no outsourcing), and, more importantly, that the preferences of individuals differ along income lines. As Galor (2011) puts it: " [The theory] hinges on the supposition that individual's preferences reflect an innate bias against child quantity beyond a certain level of income».

However, the assumption that less advantaged individuals have a stronger preference for children has been repeatedly disproved by research on fertility intentions (Berrington and Pattaro, 2014; De Wachter and Neels, 2011; Testa, 2014). While all models necessarily rest on assumptions, in neoclassical economic models, the limitations associated with the abovementioned restrictions regarding preferences and outsourcing must be added to the restrictions associated with the basic assumptions of rational choice theory (utility maximization, complete preferences, perfect information); and, crucially, with the assumption of perfect control over the reproductive process. 
Interestingly, Gary Becker's original approach to the subject avoided these pitfalls (Becker, 1960). In his original formulation, the negative relationship between income and fertility was not presented as an outcome of a trade-off between quantity and quality, but as having been mechanically caused by the omission of a key variable: i.e., knowledge about contraception ${ }^{2}$. To test this idea, Becker analyzed the relationship between income and fertility by separating couples according to whether or not they had planned their children, and indeed found a positive relationship between economic status and desired fertility.

The explanation we propose here revisits this idea, adding another key mechanism that is also usually absent from economic models: namely, the reduction in exposure associated with increasing educational attainment.

In the next section, we detail how this and other concepts are represented in our model.

\section{Model Description}

In contrast to previous models of the reproductive process, in which empirical fertility rates are used as inputs to model the transitions to different parities, here we model the decisions and behaviors that connect a given set of characteristics to events in a reproductive trajectory. The key decisions that we model are: how many children to have, and when to have them.

The first decision expresses long-term fertility preferences, and is represented in the model by the desired family size of a simulated individual. The second decision is represented through the short-term intention to have a child, which determines the likelihood and the timing of each birth.

The characteristics that we consider are related to the three transitions that have been driving fertility change since the end of the baby boom, as described in the previous sections: namely, educational attainment, birth cohort, and labor force participation. These characteristics are obtained from the empirical distributions of educational attainment and labor force participation by birth cohort, introduced in Figures $1 \mathrm{a}$ and $1 \mathrm{~b}$ for France ${ }^{3}$.

The model receives the distributions of educational attainment and labor force participation as inputs, and produces a set of simulated maternity histories as output. These maternity histories include information on the total number of children desired; the total number of children born; the maternal age at each birth; and whether each of these births was planned, mistimed, or unwanted.

\footnotetext{
${ }^{2}$ This program, which would have involved extensive data collection efforts, was quickly abandoned in favor of additional theoretical refinements (the abovementioned preference assumptions) that enabled the model to produce by itself the negative relationship between income and fertility.

${ }^{3}$ Appendix $\mathrm{C}$ presents the distributions for all countries.
} 
Once these maternity histories are obtained, any standard fertility measures can be computed (TFR, cohort fertility indicators, parity progression ratios, etc.) and compared to the observed time series of these measures in order to determine the combination of model parameters that produces the maternity histories that most closely resemble those observed in reality 4 .

By focusing on the determinants of life course events, this approach allows us to go beyond description provide a potential explanation for the observed changes in the timing and the level of fertility across time.

\subsection{Example Trajectory}

After having described the central elements of our model, we now provide a basic description of its operation through an example. A detailed technical description can be found in Appendix A and the pseudo-code of the model in Appendix B.
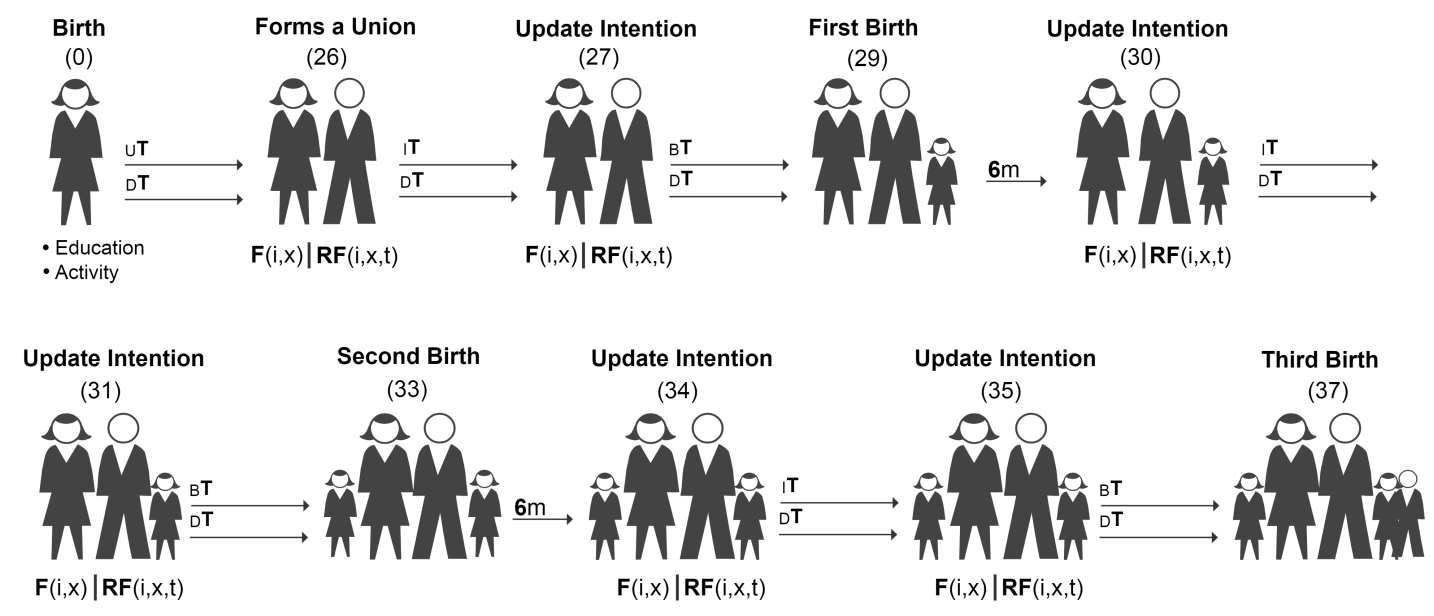

Figure 2: A Simulated Trajectory

Figure 2 depicts a hypothetical reproductive trajectory of a simulated woman born in 1940. At the woman's birth we obtain the level of education that she will achieve and decide whether she will work based on the empirical cohort trends discussed in Section 3. Let us assume she only completes primary school, and that she works.

At this point, the model will produce two waiting times: the waiting time until the formation of a union $\left.{ }_{U} T\right)$ and the waiting time until death $\left.{ }_{D} T\right)$. These events compete with each other, meaning that the event with the shortest waiting time is realized. The event that comes first

\footnotetext{
${ }^{4}$ The details of the estimation procedure are presented in Section 5
} 
in our example is the formation of a cohabiting union. The age at which the woman in our example forms a union (26) is influenced by the length of time she spends in the educational system, which depends on her educational level.

At union formation, the couple decides how many children they will try to have; i.e., they define their desired family size $D$, which will remain fixed throughout the couple's reproductive trajectory. To define their desired family size, this couple will take into account the existing social norm regarding the ideal number of children. This norm is represented by the average desired family size among young adults in the population, which implies that the couple in our example are influenced by their peers' views regarding family size.

Given that the woman in our example works, the couple will tend to prefer a family size that is smaller than the existing norm. But whether this is the case also depends on the actual number of children implied by the social norm. If the social ideal is already having a small number of children (e.g., two children), then the deviation from the norm will be smaller than if the ideal number of children is large. Although the prevailing ideal at the time the partners in our example form their union (calendar year 1966) is having three children, they decide to have two children.

After they start cohabiting, they also have to decide whether they will try to conceive a child in the next year. This decision is determined by their intention $I$. The intention of the couple in our example is, however, influenced by the time constraints they experience because they both work. These time constraints can be alleviated by having access to the resources they need to strike a better balance between work and family. In the model, these resources are approximated by her educational attainment.

The couple in our example decides not to have a child in their first year of cohabitation, which implies that they also have to avoid an unplanned conception. This, in turn, means that their risk of a conception is not determined by fecundability $F$, i.e., the monthly risk of conception for fecund women; but by residual fecundability $R F$, which refers to the risk of conception when contraception is used. Fecundability is only affected by age. Residual fecundability, by contrast, is affected by education as well as calendar time, and reflects both the increasing availability of efficient contraceptive methods and the tendency of more educated women to use contraception more consistently.

The woman in our example has low education, and the effectiveness of the most common contraceptive methods used at the time she is making this decision is limited. Nevertheless, she and her partner manage to avoid an unplanned pregnancy during their first year of marriage. Now the waiting time until death competes with the waiting time until the moment at which the couple will update their intention and make a new decision ${ }_{I} T, 12$ months later. At the end of this 12-month period, the partners decide to try to have a child. When they succeed in conceiving, a waiting time until birth ${ }_{B} T$ is generated. This results in a first birth when the woman in our example is 29 years old. The occurrence of this birth temporarily depresses 
the intention to have another child.

After the partners return to being exposed to the risk of a conception, they decide not to have another child in the first and second year after the first birth. However, in the second year, they fail to prevent an unplanned conception, which results in the woman having a second child when she is 33 years old. When the woman is 37 years old, she has a third child who is both unplanned and unwanted, as the couple had already achieved their desired family size of two children.

\section{Data \& Tools}

As mentioned in the previous sections, the main inputs of the model are the cohort distributions of educational attainment and labor force participation by educational attainment, but the model also receives observed cohort mortality rates as input for the mortality process.

The data on educational attainment and labor force participation for birth cohorts until 1980 come from the pooled census data that are available through IPUMS (Minnesota Population Center, 2018).

To obtain the labor market participation figures, we select women aged 30 to 55 by birth cohort from the pooled dataset, and obtain the proportions of these women who were active (employed + unemployed) and inactive; observations of the same women in more than one census are treated as independent. The data for the cohorts born after 1980 are obtained by forecasting from the original IPUMS series using an Exponential Smoothing State Space model, as implemented in the R Forecast package (Hyndman and Khandakar, 2008). The results of this procedure can be found in Appendix $\mathrm{C}$.

The cohort mortality rates are obtained from the Human Mortality Database (HMD, 2015). In the case of Ireland, where cohort rates are not available, we use information from Scotland, as the two countries have very similar mortality profiles.

For the estimation of the model's parameters, we rely on data on age-specific fertility rates, the evolution of the proportion of unplanned/unwanted births, and the evolution of the average desired family size (see Section 5 for details).

The age-specific fertility rates, as well as most of the other fertility indicators used in this article (Total Fertility Rates, Cohort Completed Fertility, and mean ages at birth and at different parities), come from the Human Fertility Database (2011).

The data on the proportions of unplanned/unwanted births were published by Régnier-Loilier et al. (2007) based on information from INED's 1988 Birth Control Survey (ERN), 1994 Family Situations and Employment Survey (ESFE), and the Fertility Intentions Survey (1998 - 2003). 
The information on average desired family sizes for France was obtained from Charbit (1989), which published tabulations from several fertility surveys conducted by the INED since the 1950s. These figures are based on a question about the ideal number of children en situation; i.e., the ideal number after considering the respondent's available resources. The answer to this question reflects the notion of desired family size better than the answer to the question regarding general ideals, which may not express the family size a given individual will actively try to achieve. However, the data from France indicate that the two distributions maintain a remarkably stable distance over time, with desires being situated below ideals, as expected. We use this fact to retrieve the distributions of desired family size for Ireland and Spain, for which only information on ideal family size is available (see Appendix D). Data on ideal family sizes can be found in the supplementary materials of Sobotka and Beaujouan (2014).

The model is implemented in $\mathrm{R}$ ( $\mathrm{R}$ Core Team, 2015). All files and data needed to replicate our results can be found here: github.com/dciganda.

\section{Estimation Procedure}

Our strategy consists of searching for the combination of parameter values that reduces the distance between the model output and the data available for each country.

Specifically, let $\mathcal{X} \subset \mathbb{R}^{d}$ be the parameter space, where $d$ is the number of parameters. At $p \in \mathcal{X}$ a given combination of parameter values, we compute $\mathrm{M}(p)$ the Mean Squared Error (MSE) at this location as a weighted mean of the MSEs for three vectors:

- the age-specific fertility rates between ages 14 and 50 for the period 1960-2016;

- the proportions of unplanned and unwanted births between 1968 and 19975.

- the average desired number of children.

We draw a Latin Hypercube Sample in $\mathcal{X}$ in order to learn the mapping $p \mapsto \mathrm{M}(p)$, using a Gaussian Process emulator (for the use of this approach in the context of demographic simulations, see Hilton and Bijak, 2017) fitted thanks to the R package mlegp.

We assess the accuracy of the emulator by augmenting the original sample with a set of test points. Figure 3 shows the emulator correctly predicts the value of $M$ in both the training and test sets. Finally, we determine the combination of parameters that minimizes the MSE predicted by the emulator; i.e., the combination that best fits the data.

${ }^{5}$ Systematic information on unplanned fertility is available only for France. For Ireland and Spain, the model is estimated using data on age-specific fertility rates and desired family size. In Appendix E, we perform robustness checks that show that the model is still able to accurately fit the data even in the absence of information related to unplanned fertility. 


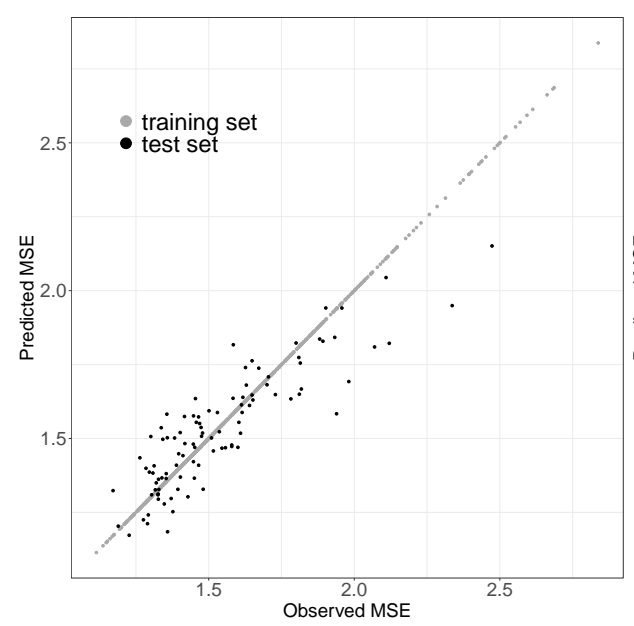

(a) France

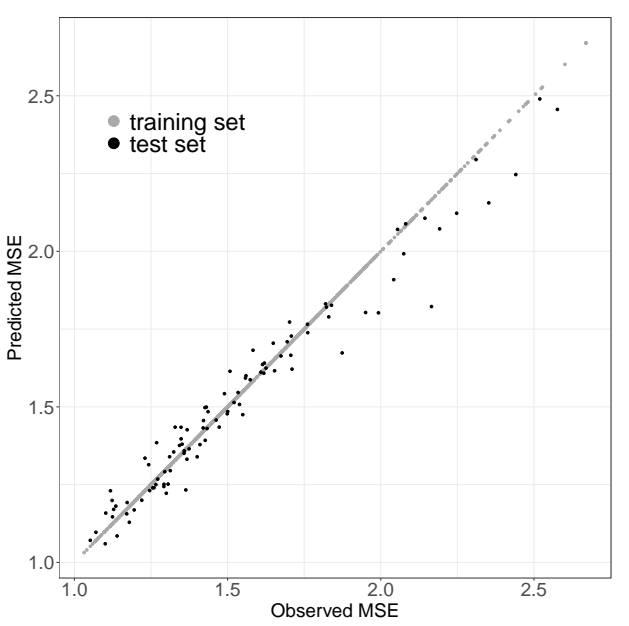

(b) Ireland

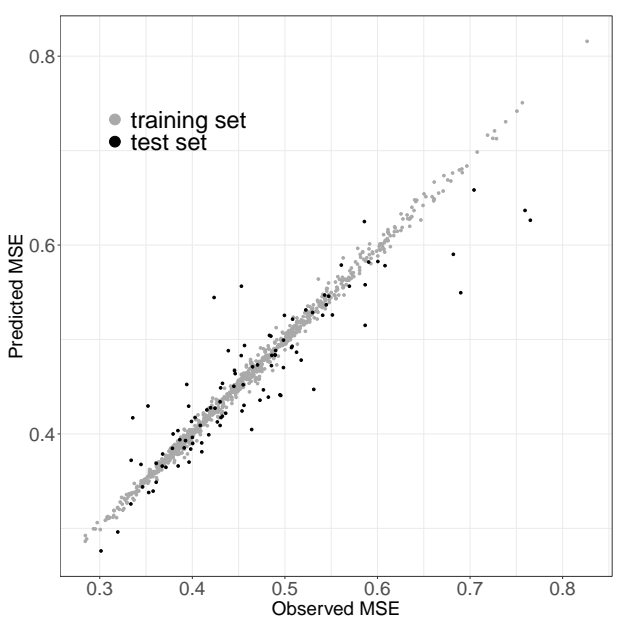

(c) Spain

Figure 3: Accuracy of the Gaussian process emulator.

The best-fitting combination of parameters for each country is reported at the end of Appendix A, the model fit and other results associated with this parametrization are presented in the next section.

\section{Results}

The model closely traces the evolution of the pattern of age-specific fertility rates in the three countries analyzed (Figure 4). Over time, the rates move downward and shift to the left, indicating the decline and the postponement of fertility. In France, the decline is very visible between the 1960s and the 1980s, but less so afterwards; while in Ireland and Spain, the 
decline continues up to the 2000s. In the model, the reduction in age-specific rates results from the combination of declines in desired family size and proportions of unplanned births, as we will discuss in more detail below. The shift to later ages, on the other hand, is produced not only by the lengthening of the period spend in education, which, in turn, leads to later ages at union formation; but by the increasing ability to space births as a consequence of the improved control over the reproductive process.

For Ireland and Spain, the predictions from the model start to diverge from the observations around the 2000s, when an early bulge in the schedule becomes visible in both countries. This mildly bi-modal pattern has been observed in other European countries as well, and appears to be driven by immigration flows (Burkimsher, 2017). As the model assumes a closed population, these changes in the schedule of fertility associated with the incorporation into the population of women with an earlier fertility pattern cannot be captured. But as we show below, this phenomenon does not have a large impact on the long-term pattern of changes in fertility rates. 
France

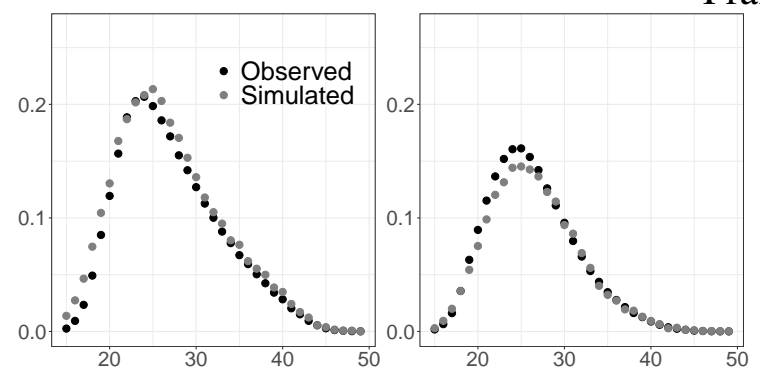

(a) 1960

(b) 1980

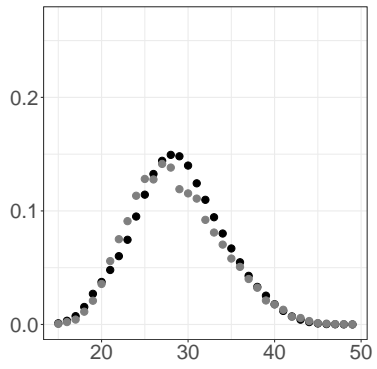

(c) 2000

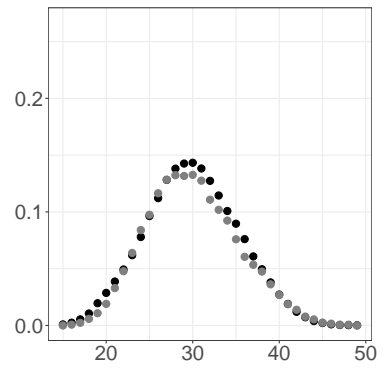

(d) 2016

Spain

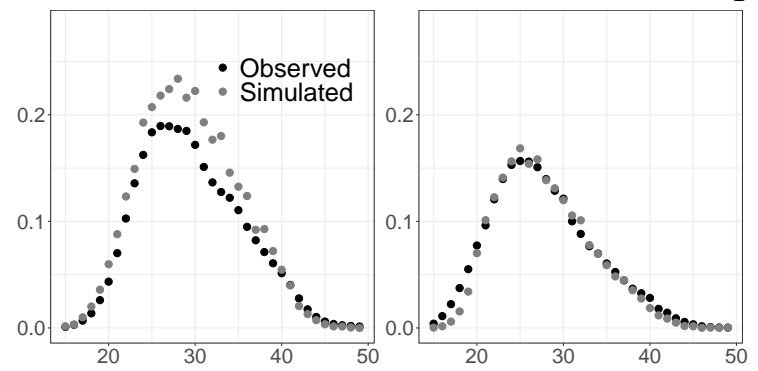

(e) 1960 (f) 1980

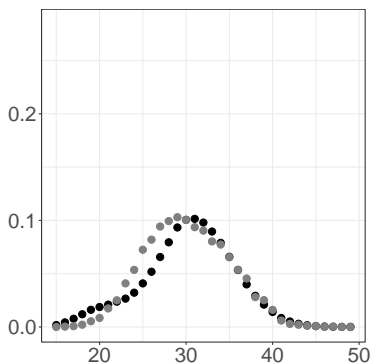

(g) 2000

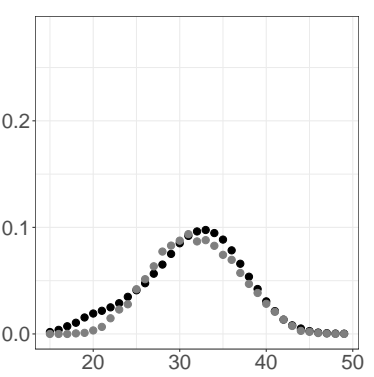

(h) 2016

Ireland

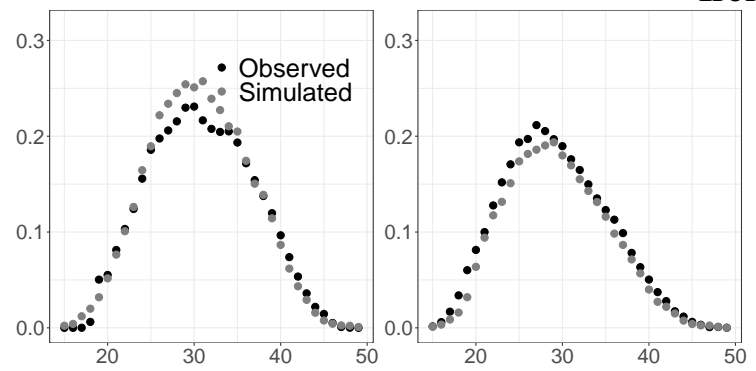

(i) 1960

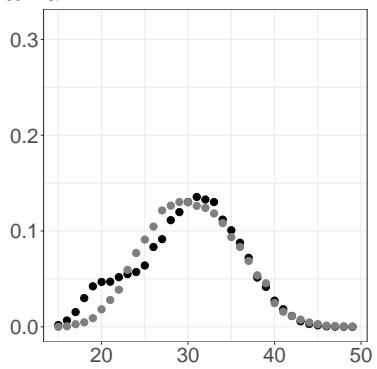

(k) 2000

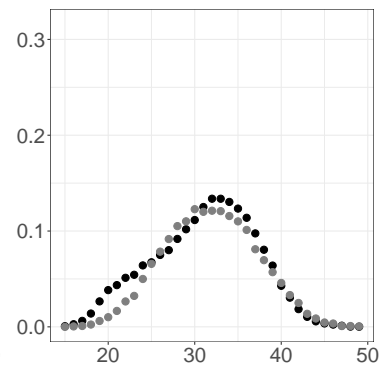

(1) 2014

Figure 4: Observed vs. Simulated Age-Specific Fertility Rates, 1960-2016, Selected Years.

As Figure 5 shows, the model also captures the evolution of desired family sizes in the three countries. Although the starting points of the observations differ, the data are in line with the notion that the desired number of children was much lower in France than in Ireland and Spain already in the mid- $20^{\text {th }}$ century. The model shows, however, that reductions in the desired family size associated with the labor market participation of women are smaller in France, which leads to a much more stable pattern over time, with a mildly declining slope. This pattern largely reflects the reinforcement of pro-natalist policies in France after the Second World War; and, in particular, the introduction of universal childcare arrangements, which have made it easier for women to combine work and family dynamics (Toulemon et al. 2008). 
In Ireland and Spain, on the other hand, the decline has been much more pronounced. In spite of this marked downward trend, the desired number of children has been consistently higher in Ireland - at least until the most recent observations, which show that this number has converged to the level in France. We can also see that in Ireland, the decline stopped abruptly around the 2000s, before falling significantly below the level of 2.5 children. This pattern is likely explained by entrenched social norms regarding family size associated with the stronger influence of the Catholic Church in the country. Spain, on the other hand, does not exhibit a similar pattern. Thus, the decline in Spain has continued to the most recent observation, and has fallen below the two-child norm.

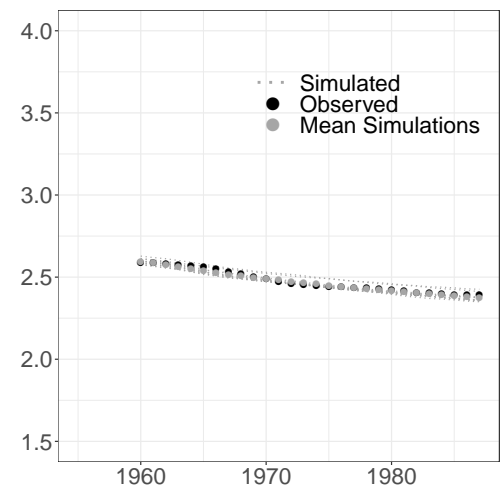

(a) France

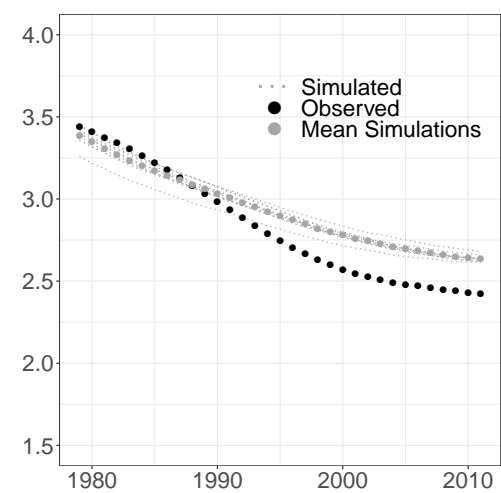

(b) Ireland

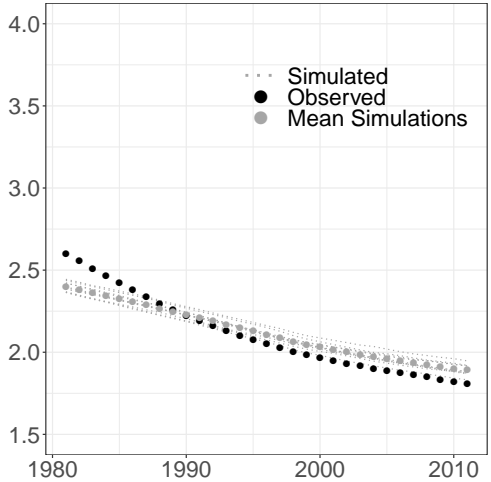

(c) Spain

Figure 5: Observed and Simulated Desired Family Size.

Firgure 6 shows the evolution of unplanned births as observed (in France) and predicted by the model. In line with previous evidence, our results show that the transition to a more controlled reproductive process occurred earlier and faster in France, which partially explains the early pattern of a small desired family size shown above. 


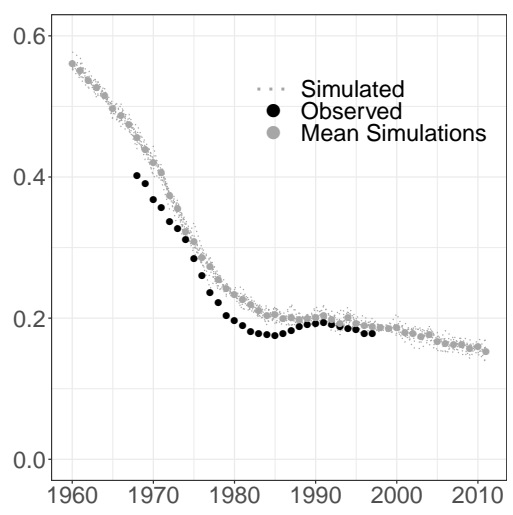

(a) France

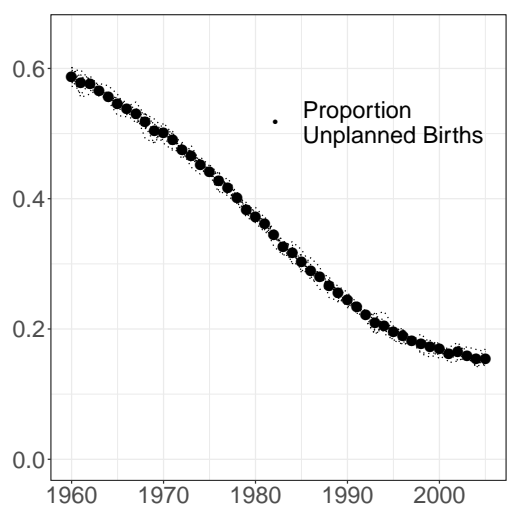

(b) Ireland

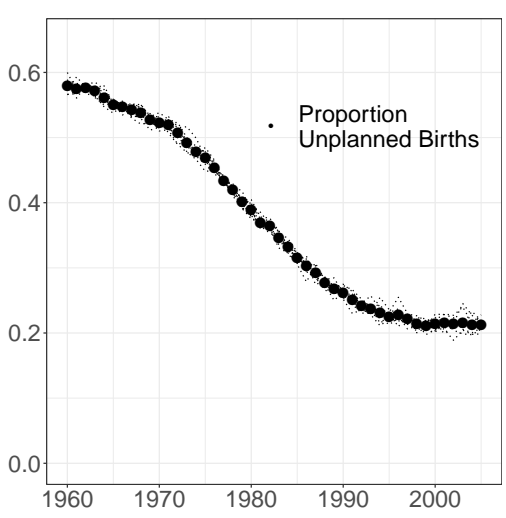

(c) Spain

Figure 6: Observed and Simulated Unplanned Births.

It is also interesting to look at the model fit with respect to the Total Fertility Rate ${ }^{6}$ Figure 7 . The model reproduces the pattern of decline and stabilization observed in the three countries.

The decline in period rates was experienced earlier in France because, compared to Ireland and Spain, France started the transition to higher education and the transition to female labor market participation earlier, and it adopted contraception and reduced unplanned fertility earlier as well. As Figure 13 in Appendix Clshows, in 1950, the proportion of women with higher education in France was close to $25 \%$ and the proportion of women in the labor market was close to $75 \%$; while the corresponding figures for Spain were $10 \%$ and $37 \%$.

The discrepancies between the data and the predictions displayed in Figure 7 occurred because although the model is able to capture systematic variation in the timing of fertility associated with cohort processes, it remains unaffected by period effects; i.e., shorter-term influences associated with, for example, the economic cycle or migration flows. Indeed, the periods with larger discrepancies coincide with periods characterized by marked timing changes, as can also be seen in Figure 8, which shows observed and simulated mean ages at birth.

In most cases, these changes are associated with exceptional situations in the labor market, including the recuperation of employment rates from the mid-1990s until the Great Recession of 2008; and with the influence of migration flows, which contributed to a slowdown in the pace of postponement, as shown above.

The finding that the TFR predicted by the model fails to capture the observed increasing trend

${ }^{6}$ The construction of the TFR rests on the notion of a synthetic cohort (treating women of different ages in a population at a given calendar time as if they belonged to a birth cohort), which makes it possible to express the information on the fertility age schedule in terms of the level of fertility achieved by this cohort. The extent to which the level of fertility of this synthetic cohort resembles that of a real cohort is diminished when the timing of fertility is changing; such patterns are known in the literature as tempo effects. 
of the late 1990s suggests that, as Bongaarts and Sobotka (2012) argued, this pattern is more closely associated with timing changes than with real changes in the level of fertility.

(a) France

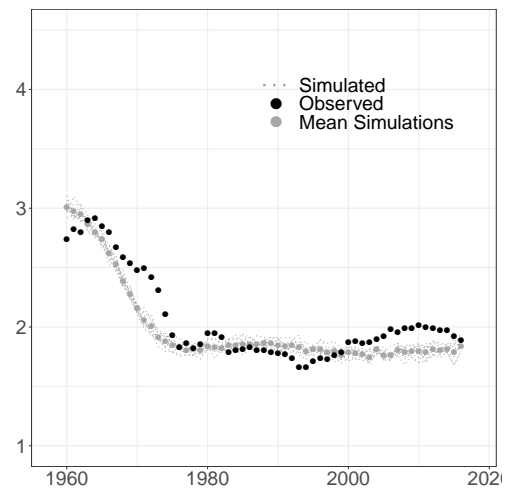

(b) Ireland

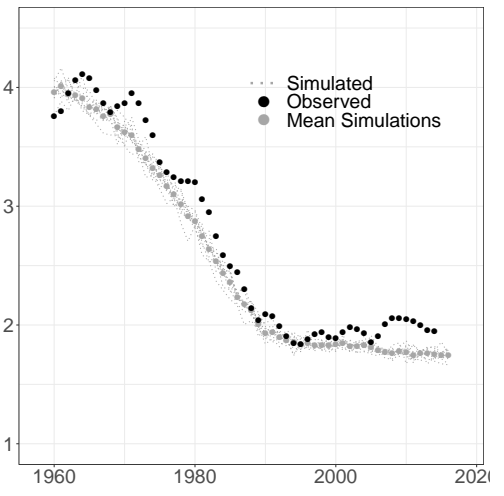

(c) Spain

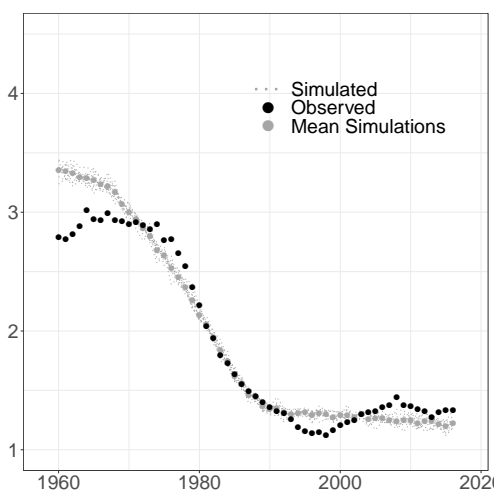

Figure 7: Observed vs Simulated Total Fertility Rate.

(a) France

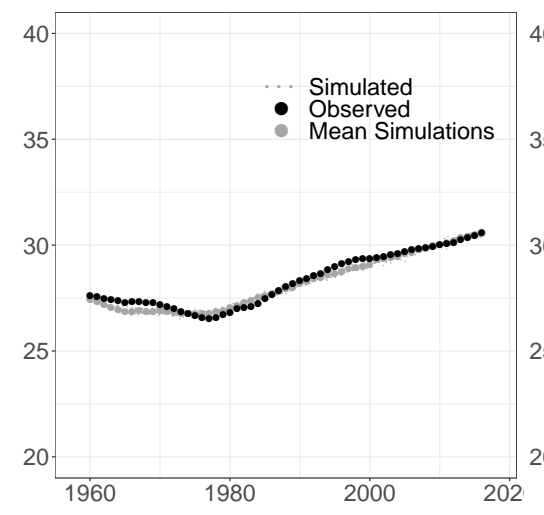

(b) Ireland

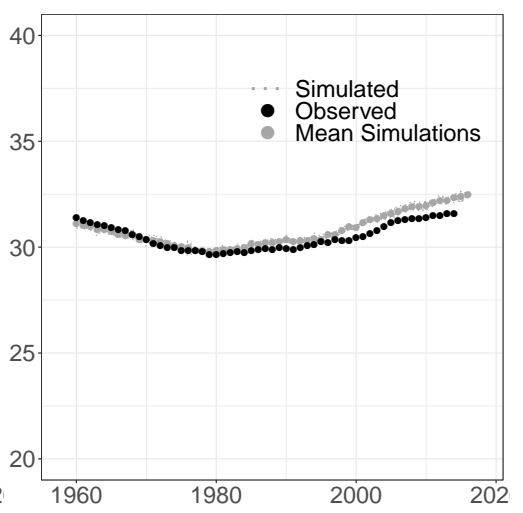

(c) Spain

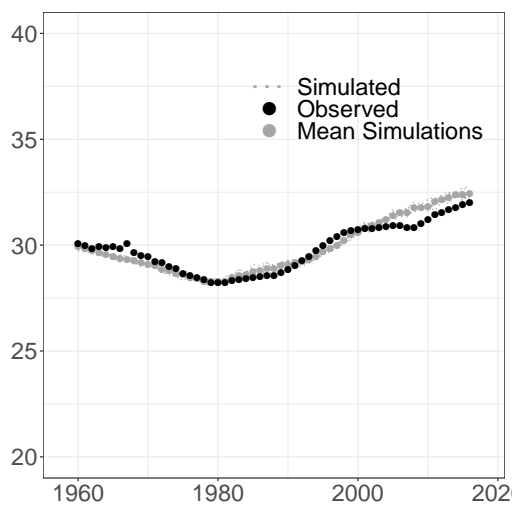

Figure 8: Observed vs Simulated Mean Age at Birth.

Changes in the level of fertility have been more gradual than suggested by the TFR as shown by the evolution of Cohort Completed Fertility (Figure 9). With the exception of Spain at the beginning of the observation window, the model captures the evolution of cohort fertility well. The decline has been more pronounced in Ireland and Spain than in France, although as suggested by the evolution of the desired family size, cohort fertility is likely to stabilize in the next years in Ireland as well. We will show this in the next section, where we present results from a number of forecasting scenarios. 
(a) France

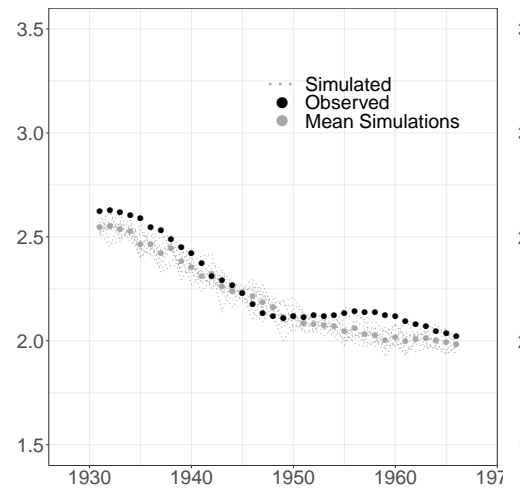

(b) Ireland

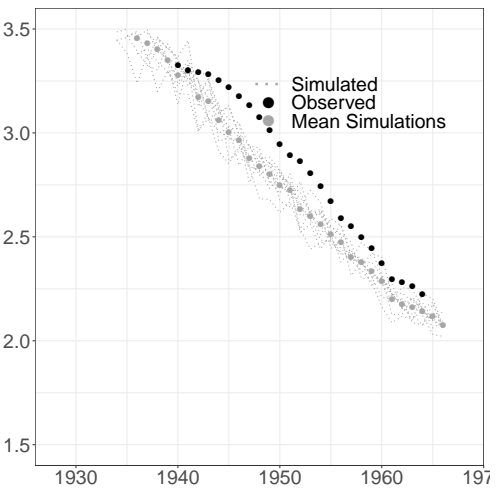

(c) Spain

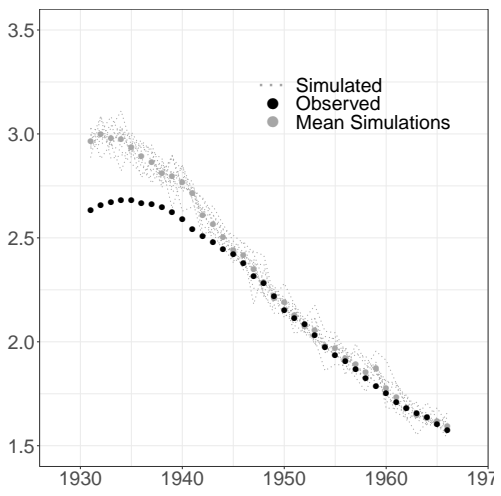

Figure 9: Observed vs Simulated Cohort Completed Fertility

\subsection{Forecasted Scenarios}

Having described the fit of the model to the observed patterns of change of different fertility indicators, we now explore a number of scenarios and associated future fertility trends with the objective of providing an answer to the question of what a potential recuperation scenario would look like in the near future.

Figure 11 presents the simulated Total Fertility Rate, Cohort Completed Fertility and Mean Age at Birth for three different scenarios, and the forecasted trends from 2016 to 2036.

The lighter line corresponds to the base scenario (scenario 1); i.e., to the prediction resulting from the best fitting combination of parameters, as presented in the previous section. These results are presented again in this context to aid with the interpretation of the magnitude of the changes implied in the other two scenarios.

The second line in the scale of grays, which sits below the other two in the three plots, corresponds to a scenario in which we keep the values of all parameters as in the base scenario, with the exception of the parameter associated with the potential positive effect of education on fertility intentions, which we set to a value associated to no effects (scenario 2). This means that in this second scenario, we do not allow for any positive effect of the expansion of education on fertility rates. In substantive terms, this scenario reflects a situation in which individuals experience all of the negative effects of their labor market participation and longer schooling on their family formation attempts, but none of the benefits.

The distance between scenarios 1 and 2 shows that the model estimates a relatively strong positive effect of educational expansion on fertility rates. According to the model, the expansion of education has contributed to the decline in fertility rates, but has also prevented 
fertility from declining further by increasing the resources available to individuals to achieve their desired family size. In other words, without allowing for a positive effect of education, the model predicts that the level of fertility would be much lower than the observed level. This positive effect seem to be stronger in France and Ireland than in Spain, and the effect is visible in both the period and the cohort indicators. As expected, scenario 2 also has the highest mean age at birth, as the restrictions implied by this scenario are expressed as both lower and later fertility.

The darker line corresponds to a scenario in which the positive effect of educational attainment on the intention is strong (scenario 3). Again, we obtain these results by changing the relevant parameter to a value that implies a larger positive effect than the one implied in the base scenario, while keeping the others constant. This scenario implies that having 12 years of education already contributes significantly to reducing the penalty on fertility intentions imposed by participation in the labor market; while in the base scenario, the number of years of education after which the penalty is reduced is 16.5 for France, 15.5 for Ireland, and 20.3 for Spain.

In substantive terms, this scenario implies that significantly larger fractions of the population are able to fulfill their fertility preferences; i.e., to have the number of children they want to have. At the aggregate level, this implies a stronger positive effect on fertility rates as the number of individuals in the population with higher education increases.

Although the mean age at birth is significantly lower in scenario 3, the fertility rates in this scenario are only slightly higher than they are in the base scenario. This finding implies that even in the presence of a strong effect of education on fertility intentions, there is no noticeable upward trend in the TFR currently or in the coming decades in any of the three countries. This result is partially explained by the fact that in all three countries, the expansion of education leads to further increases in the Mean age at Birth - which, by construction, exerts a downward pressure on the TFR, but also has a real negative effect on the level of fertility via further reductions in exposure. 


\section{France}

(a) TFR

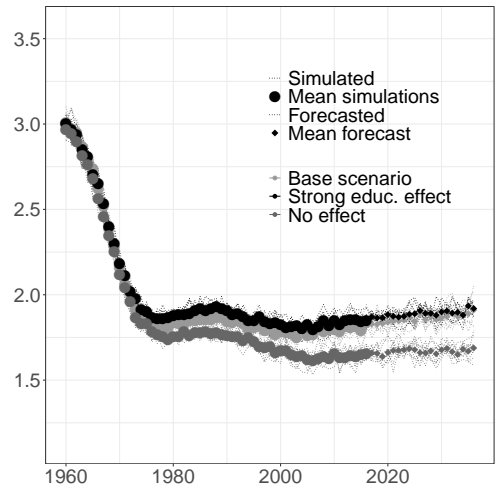

(d) TFR

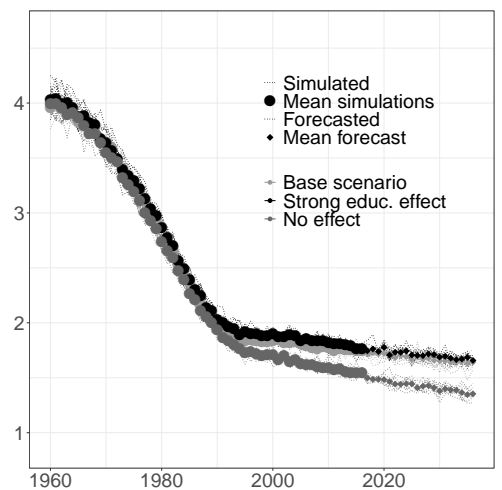

(g) TFR

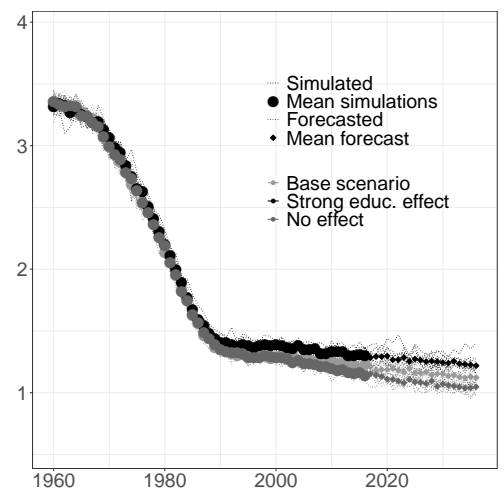

(b) Cohort Completed Fertility

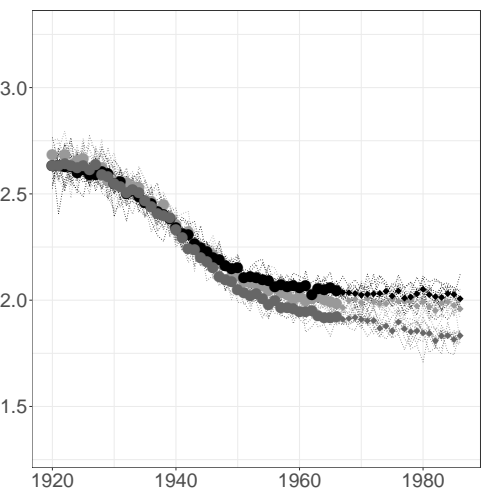

Ireland

(e) Cohort Completed Fertility

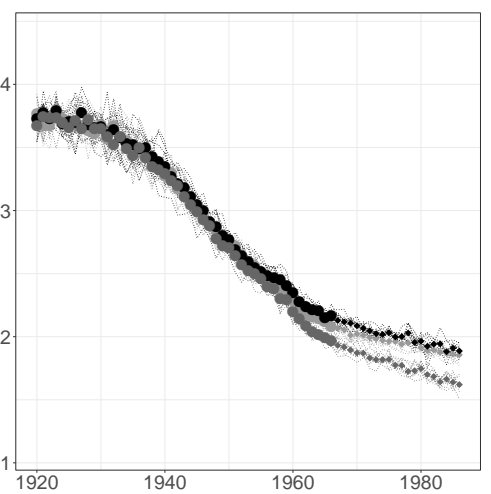

Spain

(h) Cohort Completed Fertility

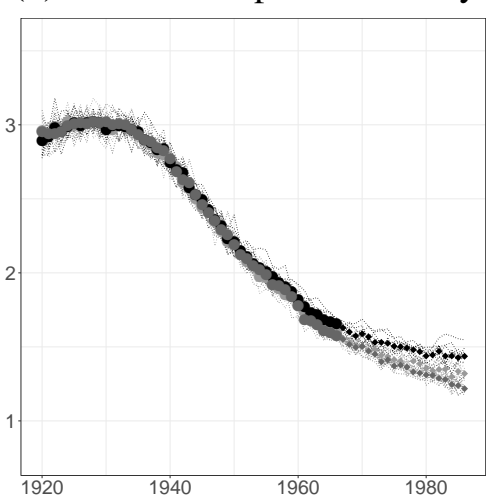

(c) Mean Age at Birth

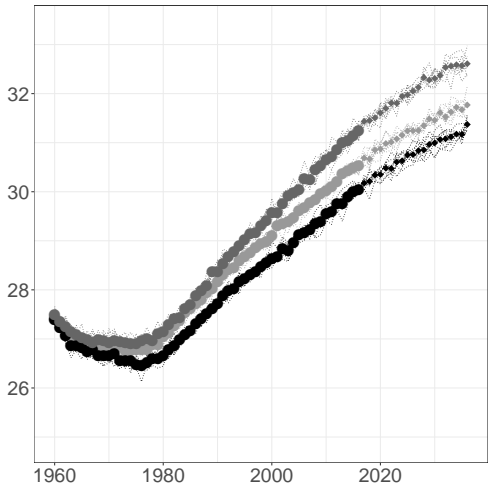

(f) Mean Age at Birth

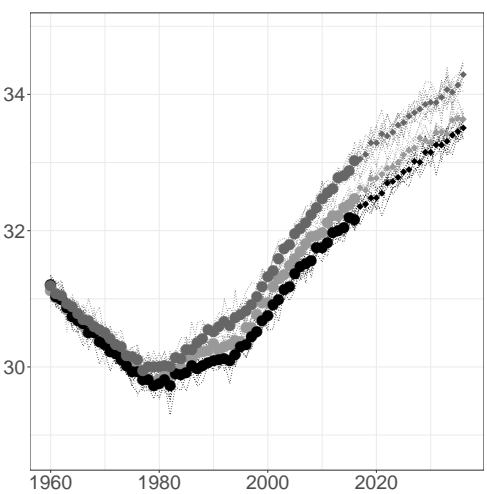

(i) Mean Age at Birth

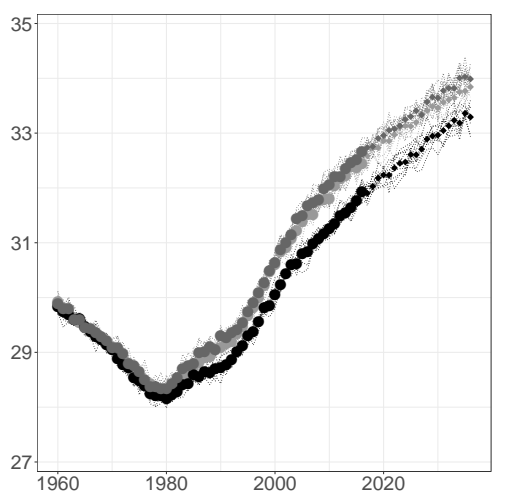

Figure 11: Forecasted Fertility Indicators

Another reason why the recuperation of fertility is not as strong in this scenario is that the 
increase in fertility associated with the reduction in the fertility gap - i.e., in the gap between the desired and the achieved number of children - is relatively modest (Figure 12). Indeed, when considered in the long run, the gap has only recently turned positive. This means that for most of the period studied individuals have had, on average, more children than they would have desired, which again highlights the importance of the contraceptive transition.

Even if the limits associated with the inability to achieve the desired family size are reduced, fertility cannot increase beyond the long-term fertility preferences.

(a) France

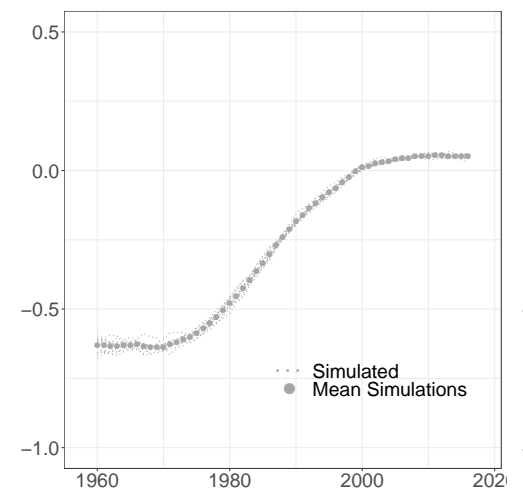

(b) Ireland

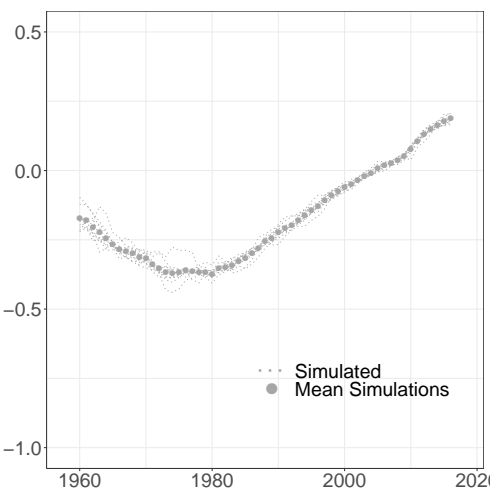

(c) Spain

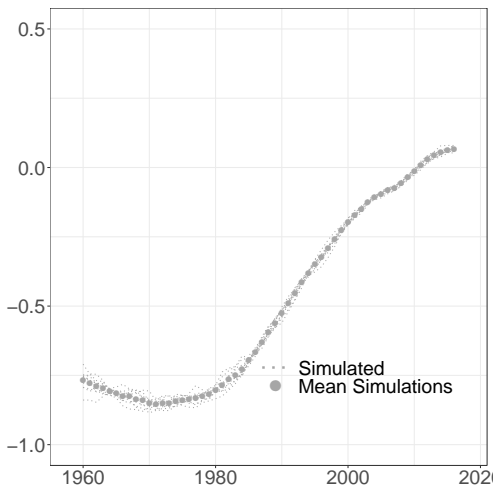

Figure 12: Simulated Fertility Gap (Achieved - Desired).

In addition to the limits imposed by fertility preferences, the recuperation of fertility via the expansion of education faces structural limits imposed by the end of the transition to higher education.

\section{Discussion}

Evidence that the relationship between development and fertility is more complex than was originally thought has been accumulating for more than a decade. During this time, less progress has been made in understanding the mechanisms that have been driving these changes. The central aim of our study was to propose an explanation for the micro-foundations of the reversal in the relationship between development and fertility, and its potential impact on the recuperation of fertility rates in the near future.

One important point that can be derived from our analysis is that a clear distinction should be made between the statistical reversal in the association between development and fertility and the recuperation of period fertility rates in industrialized countries. This reversal is not necessarily driven by larger fertility increases in more developed countries, but by the fact 
that the decline in fertility rates has been less pronounced in these countries. The comparison between France and Spain illustrates this point. While the Human Development Index was higher in France than in Spain in both 1975 and 2005, the French TFR was lower than the Spanish TFR in 1975, but was higher in 2005, which produces the reversal observed by Myrskylä et al. (2009).

This is, the reversal is explained by the earlier experience of transitions in key dimensions (education, labor market, contraception) in the countries that lead the development indicator rankings, combined with a stabilization of fertility at a higher level than that of countries in the second tier of the development ranking.

On the other hand, the recuperation of period fertility rates that was observed in most European countries at the end of the 1990s was a generalized process that - as shown by Bongaarts and Sobotka (2012) and confirmed in our analysis - was largely related to the deceleration of fertility postponement; i.e., it was not necessarily associated with a real increase in the level of fertility. Nevertheless, this conclusion might apply to a specific time period, and it does not rule out the possibility that advances in development will contribute to the recuperation of fertility at some point in the future. This was our point of departure.

Our first task was to determine whether there was a positive link between advances in development and fertility rates, and, if so, what the magnitude of such an effect might be. We examined these questions by allowing educational attainment to have a positive effect on fertility intentions, along with the other more established mechanisms through which education might have reduced achieved fertility.

The estimation of our model showed that while it is correct to argue that the process of socioeconomic development has been contributing to fertility decline, it is also necessary to understand that some of those forces were simultaneously preventing fertility from declining even further. By creating a series of counterfactual scenarios, we showed that without the increasing abilities and resources associated with the expansion of higher education, fertility rates would have been even lower, especially in the most recent years.

Our second task was to explore whether changes in the relative strength of these negative and positive influences over time would lead to a substantial recuperation of fertility in the future.

However, we identified at least three mechanisms that impose limits on this recuperation scenario.

The first of these limits is the continuing increase in the onset of family formation, as the total time spent in the educational system continues to increase among recent cohorts. Apart from the mechanical effect of timing changes on the TFR, this process has a real influence on fertility levels, as it reduces the length of time individuals in the younger cohorts spent at risk of having a child.

The second limit is imposed by long-term fertility preferences; i.e., social norms regarding 
family size. We showed that even a significant reduction in the gap between desired and achieved fertility among the recent cohorts in our model will not result in a substantial increase in fertility rates, as the distance between achieved and desired fertility might not be as large as it is often depicted.

The third and more structural limit to the recuperation of fertility rates is associated with the deceleration and eventual end of the transition to higher education. Indeed, as the three transitions that drove fertility change after the baby boom come to an end, the space for systematic variation in fertility levels will be significantly reduced.

Period rates will continue to be influenced by temporary effects associated with migration flows, labor market changes, etc. Other, more sustained changes might occur as a result of policy efforts or cultural transformations that affect the social norms regarding the ideal size of a family. It is also possible that technological improvements contribute to break the biological limits imposed by declining fecundity with age.

However, when we take into account the expected trajectories of the developments that have been the fundamental drivers of fertility in the second half of the $20^{\text {th }}$ century, the scenario of a modestly oscillating TFR is not unlikely. The final level around which the TFR will continue to oscillate will largely depend on social norms regarding the ideal number of children, and on the ability of social systems to prevent further reductions in this number by reducing the conflict between work and family demands.

In addition to producing substantive insights into the process of fertility change, our study aimed to contribute to the discussion on the methods and approaches used to study the reproductive process.

It has been more than 70 years since Louis Henry pioneered the use of simulation models to study human reproduction (Henry, 1957). This approach flourished in the decades that followed (Ridley and Sheps, 1966; Bongaarts, 1977; Dyke and MacCluer, 1973, among others). These models were primarily used to analyze natural fertility regimes (i.e., regimes in which the notion of desired family size did not exist), and to estimate in such contexts the effects of physiological and cultural factors, such as age at marriage or breastfeeding practices, on completed fertility.

This approach was later extended to regimes in which individual preferences regarding family size are important determinants of fertility rates (Bongaarts and Potter, 1983, Le Bras, 1993). These models essentially replaced as the endpoint of the reproductive process the age at which fecundability drops to zero with the age at which the desired family size is reached, while still treating family size preferences as exogenous - thereby preventing the analysis of the social determinants of fertility change. By making no attempt to explicitly model behavior, this approach remained disconnected from the larger body of research and theory focused on the socioeconomic determinants of fertility, and thus lost its centrality in the field. 
Our objective has been to breathe new life into the dynamic modeling of the reproductive process by building on existing approaches in at least three ways. First, by developing a framework that considers both the intentional and the unintentional processes that underlie fertility outcomes. Second, by representing life course events as the outcome of decisions and behaviors, which allows to go beyond description and focus on the explanation of demographic process. Finally, and following (Chazelle, 2012), by exploiting the flexibility of the language of algorithms to describe key dynamics of the reproductive processes like the influence of previous generations in the fertility decisions of individuals from the younger cohorts, or the limited ability of individuals to control their life circumstances. We hope the emerging approach will contribute to bring models of the reproductive process and theories of fertility change closer together. 


\section{A Appendix: Technical Model Description}

\section{A.1 Desired Family Size}

Our definition of desired family size attempts to capture the movement described by most analyses of post-baby boom fertility, in which the reduction in the demand for children is generally interpreted as resulting from the erosion of the male breadwinner paradigm following the rapid increase in women's participation in the labor market (Murphy, 1993). We also try to capture the influence of existing social norms at the time couples form their ideas about the appropriate family size by including a feedback loop between the micro and the macro levels. This mechanism makes the decisions of a given cohort dependent on the decisions and behavior of previous cohorts.

In the model, the desired family size $D_{i}$ of woman $i$ is formed immediately after union formation, and it is given by a Gamma distribution $]^{7}$ truncated between zero and six (desired number of children) with expected value:

$$
\mathbb{E}\left(D_{i}\right)=\bar{D}_{t[i]} \cdot\left(1 \pm\left(\frac{\delta}{1+e^{ \pm r \cdot\left(\bar{D}_{t[i]}-D^{*}\right)}}\right) \cdot p_{t[i]}\right)
$$

where $t[i]$ is the time of union formation for woman $i$, and $\bar{D}_{t[i]}$ is the average desired family size for the most recent cohorts of married women (aged 29 or younger at time $t[i]$ ), which reflects the existing norms regarding the ideal family size. Couples consider this ideal when forming their preferences. They will tend to prefer a family size that is smaller than the existing norm if the female partner in the couple is working. The amount of adjustment with respect to the norm is given by the second term in the equation. The maximum amount of adjustment is given by $\delta$. Our dual-earner couple subtracts $\delta \bar{D}_{t[i]}$ if $\bar{D}_{t[i]}$ is high. The value of the correction will, however, be progressively reduced if $\bar{D}$ approaches $D^{*}$, a parameter to be estimated. This reflects the fact that moving from an ideal of six to an ideal of five is a less costly decision than moving from an ideal of two to an ideal of one. This term is also weighted by $p_{t[i]}$, the proportion of women in the population who do not share the labor force participation status of woman $i$. This implies that when most of population share the woman's characteristics, she will take the existing norm as it is.

\footnotetext{
${ }^{7}$ This choice was based on computations we performed on data from the Integrated Value Surveys (not shown), which confirmed our expectation that the distribution of family size preferences is positively skewed, with mode in the 1-3 range, depending on country and period; and a right tail formed by a decreasing number of responses associated with larger family sizes.
} 


\section{A.2 Conception Risks}

While the desired family size $D_{i}$ is fixed at union formation and determines the attempted final parity, the intention $I_{i, t}$ varies throughout the life course, and is one of the determinants of the timing and likelihood of achieving specific parities. More specifically, the intention $I_{i, t}$ is the probability that a couple will decide to have a child in a given year. The strength of the intention depends on the individual characteristics (labor force participation and education) of the female partner, but also on the time elapsed since the previous birth. At time $t$, the intention of woman $i$ is given by:

$$
I_{i, t}=\left(\beta_{i}-\omega_{i}\right)\left(1-\cdot e^{-\lambda \cdot d_{i, t}}\right)
$$

where $\beta_{i}$ is a baseline that represents the probability of deciding to have a child in a given year for a non-working woman in a union who has not had a child recently, and has not yet achieved her desired family size.

The second term expresses the direct effect of educational attainment on the intention $I_{i, t}$ among working women. We allow this direct effect to go from neutral to positive, as it encapsulates all of the potential mechanisms through which a higher educational level might result in an advantage, conditional on a given desired family size. These include the increased ability to outsource childcare, reduce economic uncertainty, negotiate the division of housework, and mobilize personal and familial resources to strike a better balance between work and family.

We define this effect as:

$$
\omega_{i}=\frac{\eta}{1+\exp \left(\epsilon \cdot\left(y_{i}-\tau\right)\right)}
$$

which describes a logistic function that goes from $\eta$ to 0 as the number of years of education $y_{i}$ approaches the threshold $\tau$. This formulation implies not only a potential penalty of size $\eta$ on the intention $I_{i, t}$ when women work, but a potential reduction in the penalty associated with the level of education of woman $i$.

The last term in 2 models how the intention is affected by $d_{i, t}$, the time elapsed (duration) since the last birth. Parameter $\lambda$ is to be estimated. This formulation implies that there is a strong penalty immediately after childbirth, which decays exponentially as $d_{i, t}$ increases.

For couples who have decided to have a child, their waiting time to conception $w t_{c}$ is determined by their conception risk. The vast majority of models of the reproductive process represent this risk with the notion of fecundability; i.e., the probability of conceiving during a normal menstrual cycle for a women in a relationship (first defined in Gini, 1924). In the 
absence of contraception, fecundability is highest among young couples, and decreases with age as the frequency of intercourse and the biological capacity to conceive declines.

As our model is in continuous time, we adapt the notion of fecundability to this context, assuming the instantaneous risk of conception is constant (therefore drawing the waiting time to conception from an exponential distribution). The instantaneous risk is then defined such that fecundability is:

$$
F_{i, x}=\frac{\rho}{\left(1+\exp \left(\kappa \cdot\left(x_{i}-\gamma\right)\right)\right)}
$$

where the maximum fecundability $\rho$ decreases with rate $\kappa$ as the age $x_{i}$ of woman $i$ approaches $\gamma$ years of age. The timing and the strength of the decline $(\gamma$ and $\kappa)$ are estimated, and the maximum fecundability value is obtained by assuming a .95 probability of conceiving in a period of 12 months, which corresponds roughly to a monthly fecundability of 0.22 ; an estimate that has been consistently reported in the literature (Bongaarts and Potter, 1983; Leridon, 2004).

If the partners decide not to have a child in the next 12 months, they will still be subject to the risk of an unplanned conception during this period, known as residual fecundability, which is defined as:

$$
R F_{i, x, t}=F_{i, x} \cdot C_{i, t} \cdot A_{i}
$$

where $C_{i, t} \in[0,1]$ represents the effectiveness of the contraceptive methods used (if any) and is given by:

$$
C_{i, t}=\frac{\phi / y_{i}^{\alpha}}{1+e^{\theta \cdot\left(t-\left(\psi-y_{i}\right)\right)}}+v
$$

As in previous studies, we represent the adoption of effective contraception methods as a diffusion process initially led by more educated women, which progressively reaches women across strata (Rosero-Bixby and Casterline, 1993). The inflection point of this process is represented by $\psi$ and $\theta$ controls its speed, while $\phi$ represents the minimum effect (proportional reduction) of contraception on the risk of conception and $v$ the maximum. We also introduce the years of education $y$ in the formula to account for the fact that adoption is faster among more educated women; the extent of the differences among educational attainment groups if controlled by $\alpha$.

As in previous studies, we represent the adoption of effective contraception methods as a diffusion process initially led by more educated women, which progressively reaches women across socioeconomic strata (Rosero-Bixby and Casterline, 1993). The inflection point of this process is represented by $\psi$ and $\theta$ controls its speed, while $\phi$ represents the minimum 
effect (proportional reduction) of contraception on the risk of conception, and $v$ represents the maximum effect. We also introduce the years of education $y$ in the formula to account for the observation that adoption is faster among more educated women; i.e., for the extent of the differences among educational attainment groups if controlled by $\alpha$.

The last term in equation 5, $A_{i}$ represents an additional effect of contraception on the risk of conception after the partners in a couple have achieved their desired family size. The assumption here is that the partners will intensify their efforts to prevent additional births after they have reached their goal; or, in other words, that mistimed and unwanted births have significantly different associated risks.

If the waiting time until conception (planned or unplanned) ${ }_{C} T$ is shorter than 12 months, a waiting time until birth ${ }_{B} T$ is created by adding 270 days of gestation to ${ }_{C} T$. Following the birth, there will be a period of six months that corresponds to the period of postpartum subfecundity, abstinence, and increased contraceptive use with the aim of avoiding dangerously close births. After this period of time, the couple will go back to being exposed to the risk of a new conception.

If no conception occurs within the next 12 months, our couple will update their intentions again at the end of that period. Thus, the partners will either decide to try to have a child in the next year, or they will be subject to the risk of an unplanned birth.

\section{A.3 Age at Union Formation}

To keep things simple, the preferences, intentions, and risks that control the process described so far are assumed to operate only after the formation of a cohabitation union. The age at which this event occurs is therefore of great importance. We follow previous studies that have successfully approached the empirical distribution in the age at marriage using the Lognormal distribution (Mode, 1985).

$$
\ln \left(M_{i}\right) \sim \mathcal{N}\left(\mu_{i}, \sigma^{2}\right)
$$

with $\mu_{i}=y_{i}+\xi$, where $y_{i}$ is the numbers of years of education of woman $i$, and parameter $\xi$ is the average waiting time (in years) to the formation of a cohabiting union after the end of the schooling period.

\section{A.4 Death}

The waiting time until death is sampled using the inverse distribution function method (for a description of the method see: Willekens, 2009), where the distribution of waiting times until 
death is reconstructed using age-specific cohort mortality rates.

\section{A.5 Parameter Estimates}

Table 1 provides the optimal combination of parameters for the three countries studies (columns 5 to 7). The table also provides information on the domain associated with each parameter (column 2), and on the equation to which they belong (column 3).

Table 1: Estimated values of model parameters

\begin{tabular}{|c|c|c|c|c|c|c|}
\hline Name & Domain & Eq. & Description & \multicolumn{3}{|c|}{ Value } \\
\hline & & & & FR & ES & IR \\
\hline $\bar{D}_{t 0}$ & desired fam. size & 1 & initial value of $\bar{D}$ & 2.86 & 2.85 & 4.98 \\
\hline$D^{*}$ & desired fam. size & 1 & inflection point resistance $D$ & 2.35 & 1.78 & 2.65 \\
\hline$\delta$ & desired fam. size & 1 & effect on $D$ of working & 0.17 & 0.18 & 0.24 \\
\hline$\eta$ & intention & 3 & penalty on intention of working & 0.55 & 0.53 & 0.55 \\
\hline$\tau$ & intention & 3 & years of edu. after which $\eta$ is reduced & 16.5 & 20.3 & 15.5 \\
\hline$\gamma$ & fecundability & 4 & inflection point of decline (age) & 39.7 & 38.3 & 38.3 \\
\hline$\kappa$ & fecundability & 4 & speed of decline with age & 0.54 & 0.7 & 0.67 \\
\hline$A$ & contraception & 5 & additional effect due to achieved $D$ & 0.069 & 0.076 & 0.067 \\
\hline$\phi$ & contraception & 6 & minimum effect on conception risk & 0.39 & 0.63 & 0.77 \\
\hline$v$ & contraception & 6 & maximum effect on conception risk & 0.03 & 0.03 & 0.03 \\
\hline$\psi$ & contraception & 6 & inflection year in the diffusion process & 1971.4 & 1977.8 & 1977.9 \\
\hline$\theta$ & contraception & 6 & speed of the diffusion & 0.23 & 0.16 & 0.14 \\
\hline$\xi$ & age union form. & 7 & time to union after schooling & 3.2 & 7.5 & 5.2 \\
\hline
\end{tabular}




\section{B Appendix: Comfert Algorithm}

We represent the reproductive process with a discrete event simulation (DEVS) (Zeigler et al. 2000), in which time advances with the realization of four different types of events: namely, starting a cohabiting union, deciding to have a child, having a child, and dying.

The pseudo-code introduced here details the state changes related to the experience of each of these events. At each iteration, the algorithm finds the event with the shortest waiting time from a list of all possible events for the entire population of simulated individuals. After the realization of the next event, the state of the system and the clock are updated, and the simulation can continue to the next run

\section{The Comfert Algorithm}

\section{read input data}

\section{initialization}

generate wts to birth in the first year

While time < end time do

choose next event $\rightarrow$ n_event

update clock

update ages \& waiting times

if $n \_$event $=$birth then

\section{if girl then}

add to population

education level

labor force participation

wt to union

wt to death

end

update indicators of mother:

age at birth

nr. children

nr. children left

wt to intention update

end

if $n \_$event $=$death then

| remove from the population

end if $n \_$event $=$union formation then

desired family size

if intention $>x \sim U(0,1)$ then wt conception $\rightarrow F_{i, x}$

else

wt conception $\rightarrow R F_{i, x, t}$

end

update wt to intention update

end

if $n . e v e n t=$ intention update then update intention

if intention $>x \sim U(0,1)$ then

wt conception $\rightarrow$ by $F_{i, x}$

else

| wt conception $\rightarrow R F_{i, x, t}$

end

wt to intention update

end

if year change then

remove those with age $>$ max_age

compute indicators.

end

save output

asfrs; unplanned births;

desired family size. 


\section{Appendix: Forecasted Input Distributions}

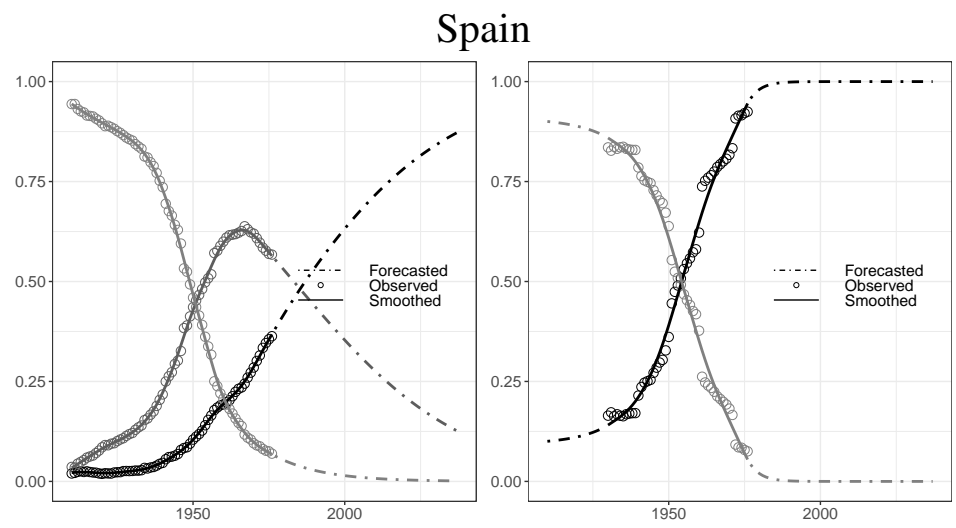

$\begin{array}{ll}\text { (a) Educational Attainment } & \text { (b) Labor Force Participation }\end{array}$ France
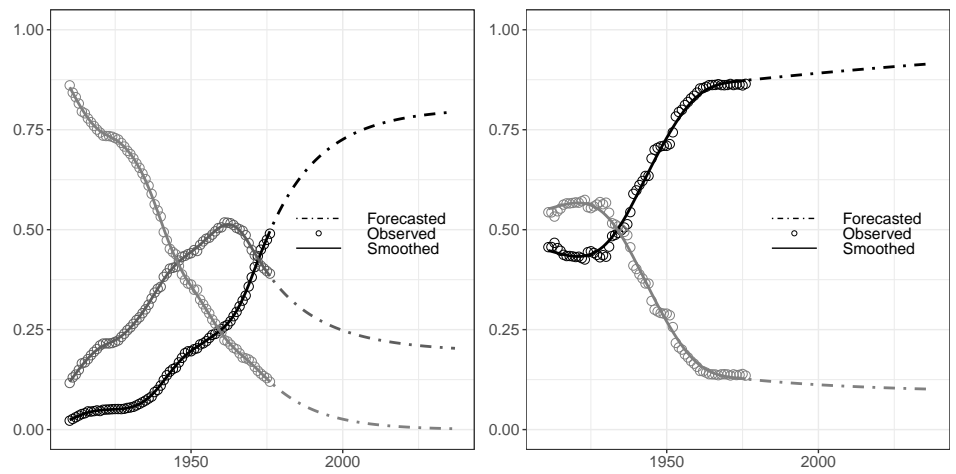

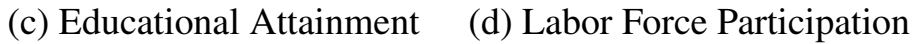
Ireland
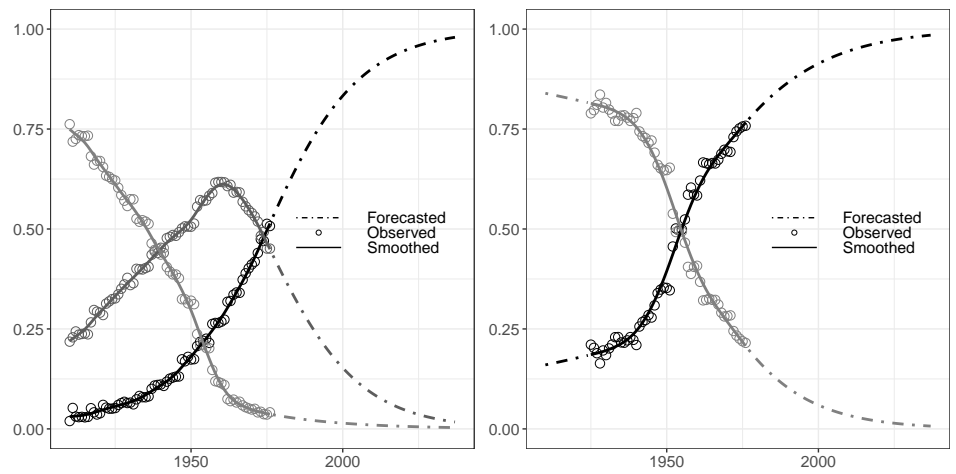

(e) Educational Attainment

(f) Labor Force Participation

Figure 13: Observed and Forecasted Distributions of Educ. Attainment and Labor Force Participation. 


\section{Appendix: Desired (from Ideal) Family Size}

As we mentioned in Section 4, the information available for Ireland and Spain refers to the ideal instead of desired family size. It is, however, possible to exploit the fact that there is a systematic difference between these two distributions, as seen in (Figure 14a), which shows observed time series of ideal and desired (ideal en situation) family sizes in France. Figures $14 \mathrm{c}$ and $14 \mathrm{c}$ show the resulting distribution of desired family sizes for Ireland and Spain, under the assumption that the distance between the ideal and the desired sizes is the same as it is in France.

(a) France

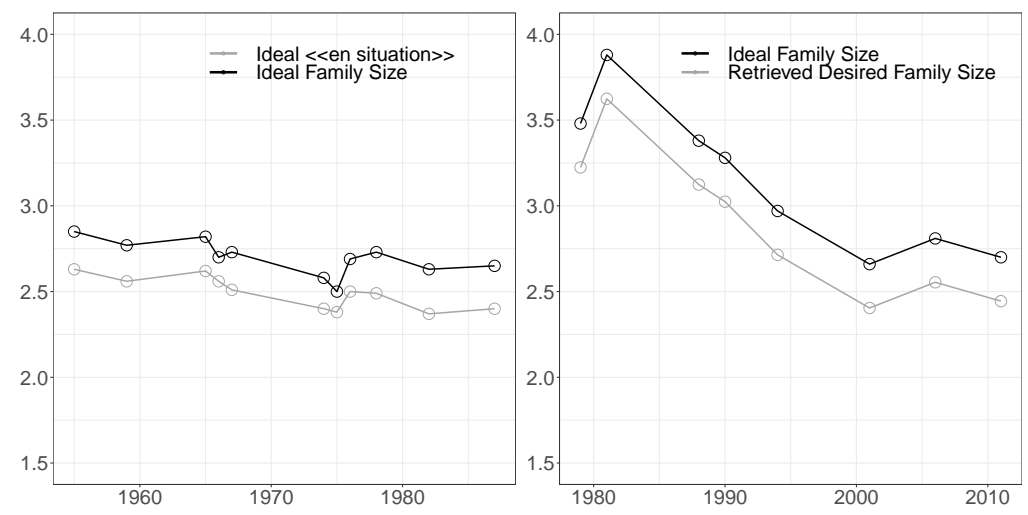

(c) Spain

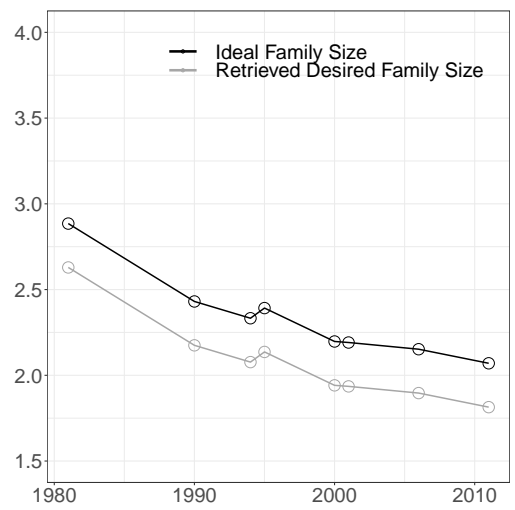

Figure 14: Ideal vs Desired Family Size I France, Ireland, Spain 


\section{E Appendix: Indirect Estimation of the Contraceptive Tran- sition}

We now illustrate another potential use of our model, which also serves as a robustness check. The lighter line in Figure 15a corresponds to the proportions of unplanned births in France (simulated using the combination of parameters that minimized the distance between the model output and the data). As has already been shown in Figure 6a, there is a strong fit between the simulated and observed proportions. This result is expected, as the observed proportions were involved in the estimation of the model parameters. For Ireland and Spain (Figures $15 \mathrm{~b}$ and 15c), it is not possible to assess the reliability of the model estimates, because we do not have information on the contraceptive transition in these countries. We can, however, assess the capacity of the model to estimate the parameters related to the contraceptive transition in the absence of information; i.e., by creating a scenario in which we assume that the information is also missing for France. In practical terms, this means re-running the estimation by assigning a zero weight to the proportions of unplanned/unwanted births. The simulated proportions of unplanned births obtained from this exercise are represented by the dark line in Figure 15a. The correspondence to the estimated proportions with (lighter gray line) and without (darker gray line) is not total, but it suggests that the model can produce estimates that are close to the true values, while relying exclusively on data on desired family size and age-specific fertility rates.

(a) France

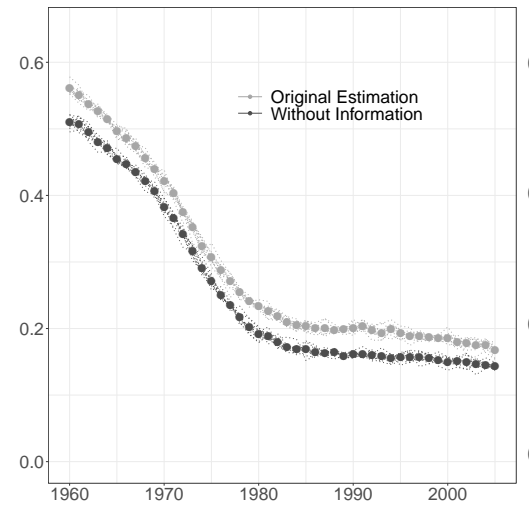

(b) Spain

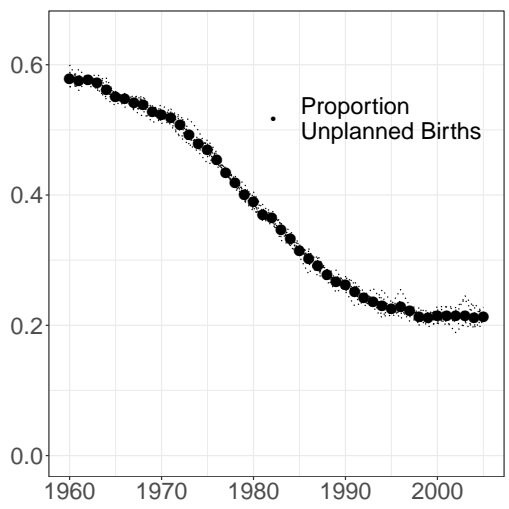

(c) Ireland

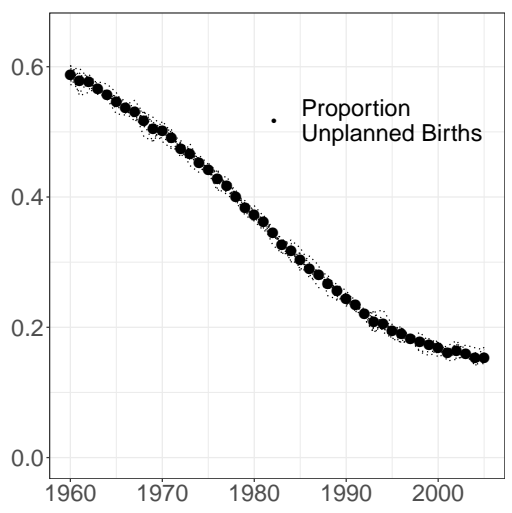

Figure 15: Direct vs Indirect Estimates of the Proportions of Unplanned Births 


\section{References}

Ahn, N. and P. Mira (2002). A note on the changing relationship between fertility and female employment rates in developed countries. Journal of population Economics 15(4), 667682.

Basten, S. (2013). Re-examining the fertility assumptions for pacific asia in the un's 2010 world population prospects. University of Oxford Department of Social Policy and Intervention, Barnett Papers in Social Research 1.

Becker, G. S. (1960). An economic analysis of fertility. In Demographic and economic change in developed countries, pp. 209-240. Columbia University Press.

Becker, G. S. and H. G. Lewis (1973). On the interaction between the quantity and quality of children. Journal of political Economy 81(2, Part 2), S279-S288.

Becker, G. S. and N. Tomes (1976). Child endowments and the quantity and quality of children. Journal of political Economy 84(4, Part 2), S143-S162.

Berrington, A. and S. Pattaro (2014). Educational differences in fertility desires, intentions and behaviour: A life course perspective. Advances in life course research 21, 10-27.

Bongaarts, J. (1977). A dynamic model of the reproductive process. Population Studies 31(1), 59-73.

Bongaarts, J. (1997). Trends in unwanted childbearing in the developing world. Studies in Family planning, 267-277.

Bongaarts, J. and R. E. Potter (1983). Fertility, biology, and behavior: An analysis of the proximate determinants. Academic Press.

Bongaarts, J. and T. Sobotka (2012). A Demographic Explanation for the Recent Rise in European Fertility. Population and Development Review 38(1), 83-120.

Burkimsher, M. (2017). Evolution of the shape of the fertility curve: Why might some countries develop a bimodal curve? Demographic Research 37, 295-324.

Caldwell, J. C. and T. Schindlmayr (2003). Explanations of the fertility crisis in modern societies: A search for commonalities. Population studies 57(3), 241-263.

Casterline, J. B. and L. O. El-Zeini (2007). The estimation of unwanted fertility. Demography 44(4), 729-745.

Charbit, Y. (1989). L'opinion sur la politique démographique, la nuptialité et les nouvelles techniques de procréation en mai 1987. Population 44(6), 1159-1187. 
Chazelle, B. (2012). Natural algorithms and influence systems. Communications of the ACM 55(12), 101-110.

De Wachter, D. and K. Neels (2011). Educational differentials in fertility intentions and outcomes: family formation in flanders in the early 1990s. Vienna Yearbook of Population Research, 227-258.

Dyke, B. and J. W. MacCluer (1973). Computer simulation in human population studies.

Easterlin, R. A. (1978). What will 1984 be like? socioeconomic implications of recent twists in age structure. Demography 15(4), 397-432.

Esping-Andersen, G. and F. C. Billari (2015). Re-theorizing family demographics. Population and Development Review 41(1), 1-31.

Galor, O. (2011, May). The demographic transition: Causes and consequences. Working Paper 17057, National Bureau of Economic Research.

Gini, C. (1924). Premières recherches sur la fécondabilité de la femme. In North-Holland: (Ed.), Proceedings of the International Mathematical Congress., Volume Vol. 2., Toronto.

Goldscheider, F., E. Bernhardt, and T. Lappegård (2015). The gender revolution: A framework for understanding changing family and demographic behavior. Population and Development Review 41(2), 207-239.

Goldstein, J. R., T. Sobotka, and A. Jasilioniene (2009). The End of "Lowest-Low" Fertility? Population and Development Review 35(4), pp. 663-699.

Henry, L. (1957). Fécondité et famille. Population 12(3), 413-444.

Hilton, J. and J. Bijak (2017). Design and analysis of demographic simulations. In Agentbased modelling in population studies, pp. 211-235. Springer.

HMD (2015). Human Mortality Database. University of California, Berkeley (USA), and Max Planck Institute for Demographic Research (Germany). Available at www.mortality.org or www.humanmortality.de (data downloaded on May 2015).

Human Fertility Database, . (2011). Human fertility database.

Hyndman, R. J. and Y. Khandakar (2008). Automatic time series forecasting: the forecast package for R. Journal of Statistical Software 26(3), 1-22.

Jones, L. E., A. Schoonbroodt, and M. Tertilt (2008). Fertility theories: can they explain the negative fertility-income relationship? Technical report, National Bureau of Economic Research. 
Klijzing, E. (2000). Are there unmet family planning needs in europe? Family planning perspectives, 74-88.

Le Bras, H. (1993). Simulation of change to validate demographic analysis. Oxford England Clarendon Press 1993.

Leridon, H. (2004). Can assisted reproduction technology compensate for the natural decline in fertility with age? a model assessment. Human Reproduction 19(7), 1548-1553.

Luci-Greulich, A. and O. Thévenon (2014). Does economic advancement 'Cause'a reincrease in fertility? An empirical analysis for OECD countries (1960-2007). European Journal of Population 30(2), 187-221.

Minnesota Population Center, . (2018). Integrated public use microdata series, international: Version 7.0.

Mode, C. J. (1985). Stochastic processes in demography and their computer implementation, Volume 14. Springer Science \& Business Media.

Murphy, M. (1993). The contraceptive pill and women's employment as factors in fertility change in britain 1963-1980: A challenge to the conventional view. Population studies 47(2), 221-243.

Myrskylä, M., H.-P. Kohler, and F. C. Billari (2009). Advances in development reverse fertility declines. Nature 460(7256), 741-743.

R Core Team (2015). R: A Language and Environment for Statistical Computing. Vienna, Austria: R Foundation for Statistical Computing.

Raftery, A. E., L. Alkema, and P. Gerland (2014). Bayesian population projections for the united nations. Statistical science: a review journal of the Institute of Mathematical Statistics 29(1), 58 .

Régnier-Loilier, A., H. Leridon, F. Cahen, et al. (2007). Four decades of legalized contraception in france: an unfinished revolution? Technical report, Institut National d'Études Démographiques (INED).

Ridley, J. C. and M. C. Sheps (1966). An analytic simulation model of human reproduction with demographic and biological components. Population Studies 19(3), 297-310.

Rindfuss, R. R. and K. L. Brewster (1996). Childrearing and fertility. Population and Development Review 22, 258-289.

Rosero-Bixby, L. and J. B. Casterline (1993). Modelling diffusion effects in fertility transition. Population Studies 47(1), 147-167. 
Sobotka, T. and É. Beaujouan (2014). Two Is Best? The Persistence of a Two-Child Family Ideal in Europe. Population and Development Review 40(3), 391-419.

Testa, M. R. (2014). On the positive correlation between education and fertility intentions in europe: Individual-and country-level evidence. Advances in life course research 21, 28-42.

Toulemon, L., A. Pailhé, and C. Rossier (2008). France: high and stable fertility. Demographic Research 19(16), 503-556.

United Nations, P. D. (2010). World population prospects: The 2010 revision. Department of Economic and Social Affairs.

Willekens, F. (2009). Continuous-time microsimulation in longitudinal analysis. New frontiers in microsimulation modelling, 353-376.

Zeigler, B. P., T. G. Kim, and H. Praehofer (2000). Theory of modeling and simulation. Academic press. 